\title{
2011/31
}

Implementing steady state efficiency in overlapping generations economies with environmental externalities

Nguyen Thang Dao and Julio Davila

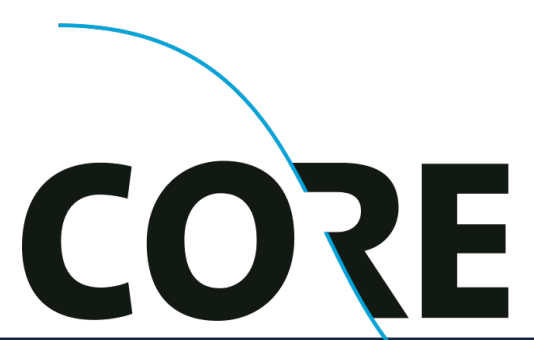

DISCUSSION PAPER

Center for Operations Research and Econometrics

Voie du Roman Pays, 34 B-1348 Louvain-la-Neuve Belgium http://www.uclouvain.be/core 


\title{
CORE DISCUSSION PAPER
}

$2011 / 31$

\section{Implementing steady state efficiency in overlapping generations economies with environmental externalities}

\author{
Nguyen Thang DAO ${ }^{1}$ and Julio DAVILA ${ }^{2}$
}

\begin{abstract}
June 2011
Abstract

We consider in this paper overlapping generations economies with pollution resulting from both consumption and production. The competitive equilibrium steady state is compared to the optimal steady state from the social planner's viewpoint. We show that the dynamical inefficiency of competitive equilibrium steady state with capital-labor ratio exceeding the golden rule ratio still holds. Moreover, the range of dynamically efficient steady state capital ratios increases with the effectiveness of the environment maintainance technology, and decreases for more polluting production technologies. We characterize some tax and transfer policies that decentralize as a competitive equilibrium outcome the transition to the social planner's steady state.
\end{abstract}

Keywords: overlapping generations, environmental externality, tax and transfer policy.

JEL Classification: D62, E21, H21, H41

\footnotetext{
${ }^{1}$ Université catholique de Louvain, CORE, B-1348 Louvain-la-Neuve, Belgium; Vietnam Centre for Economic and Policy Research (VEPR), Hanoi, Vietnam.E-mail: nguyen.dao@uclouvain.be 2 Université catholique de Louvain, CORE, B-1348 Louvain-la-Neuve, Belgium; Paris School of Economics, France. E-mail: Julio.davila@uclouvain.be. This author is also member of ECORE, the association between CORE and ECARES

The authors gratefully thank funding from a research grant "Mobilité Ulysse F.R.S.-FNRS" from the Belgian FNRS.

This paper presents research results of the Belgian Program on Interuniversity Poles of Attraction initiated by the Belgian State, Prime Minister's Office, Science Policy Programming. The scientific responsibility is assumed by the authors.
} 


\section{Introduction}

Environmental externalities have been studied in economies with overlapping generations since long. In particular, the effects of environmental externalities on dynamic inefficiency, productivity, health and longevity of agents have been addressed, as well, as the policy interventions that may be needed. While in most papers pollution is assumed to come from production, and the environment is supposed to improve or degrade by itself at a constant rate (Marini and Scaramozzino 1995; Jouvet et al 2000; Jouvet, Pestieau and Ponthiere 2007; Pautrel 2007; Gutiérrez 2008), other papers assume that pollution comes from consumption (John and Pecchenino 1994; John et al. 1995; Ono 1996). As a consequence of the differing assumptions, the effect of environmental externalities on capital accumulation vary widely across papers. Specifically, John et al. (1995) showed that when only consumption pollutes, the economy accumulates less capital than what would be optimal. Conversely, Gutiérrez (2008) showed that when only production pollutes, the economy accumulates instead more capital than the optimal level. This is so because in John et al. (1995) agents pay taxes to maintain environment when young, so that an increased pollution reduces their savings; however, in Gutiérrez (2008) pollution increases health costs in old age, leading agents to save more to pay for them. The difference seems therefore to come from when the taxes are paid (when young or old) rather than from whether pollution comes from production or consumption. Another main difference between John et al. (1995) and Gutiérrez (2008) is their different assumptions about the ability of environment to recover from pollution. John et al. (1995) assumes that environment naturally degrades over time, while Gutiérrez (2008) assumes that environment recovers naturally.

This paper aims at identifying the net impact of both production and consumption on environment by allowing for the two types of pollution simultaneously. Moreover, as in John et al. (1994, 1995), we assume that the environment degrades naturally over time at a constant rate and that young agents devote part of their income to maintain it. ${ }^{3}$ In this setup, we characterize the range of dynamically inefficient capital-labor ratios. Next, we introduce taxes and transfer policies that decentralize the first-best steady state and transition to it as a competitive equilibrium steady state.

The rest of the paper is organized as follows. Section 2 introduces the model. Section 3 characterizes its competitive equilibria. Section 4 presents the problem of the social planner, defines the efficient allocation with and without discounting, and characterizes the range of dynamically inefficient capital ratios (Proposition 1). The competitive equilibrium steady state and the planner's steady state are compared in Section 5, where we introduce some tax and transfer schemes that decentralize the planner's steady state and the transition to it as market outcome (from Proposition 2 to Proposition 5). Section 6 concludes the paper.

\section{The model}

We consider the overlapping generations economy in Diamond (1965) with a constant population of identical agents. At each period $t$ output can be produced out of capital and

\footnotetext{
${ }^{3}$ In John et al. $(1994,1995)$, only the consumption of old agents pollutes, young agents do not consume. In Ono (1996), it is assumed that consumption of both young and old agents degrade the environment but with a period lag. Here, we assume also that consumptions of both old and young agents and production pollute without decay.
} 
labor according to a constant returns to scale neoclassical production function $F\left(K_{t}, L_{t}\right)$. This production is assumed to satisfy the condition $F_{K}(k, 1)+F_{K K}(k, 1) k>0$ for all $k>0$ where $k=K / L$, which guarantees the existence of competitive equilibrium dynamics (see Appendix 3). Note that this property holds for all Constant Elasticity of Substitution (CES) production functions $F\left(K_{t}, L_{t}\right)=\left[\theta K_{t}^{\rho}+(1-\theta) L_{t}^{\rho}\right]^{1 / \rho}, \theta \in(0,1), \rho \in(-\infty, 1]$. Capital fully depreciates in each period. The representative firm maximizes profits solving under perfect competition

$$
\underset{K_{t}, L_{t} \geq 0}{\operatorname{Max}} F\left(K_{t}, L_{t}\right)-r_{t} K_{t}-w_{t} L_{t}
$$

so that the rental rate of capital and wage rate are, in each period $t$, the marginal productivity of capital and labor respectively, i.e.

$$
\begin{aligned}
& r_{t}=F_{K}\left(K_{t}, L_{t}\right) \\
& w_{t}=F_{L}\left(K_{t}, L_{t}\right)
\end{aligned}
$$

The size of each generation is normalized to one. Each agent lives two periods, say young and old. When young, an agent is endowed with one unit of labor which he supplies inelastically, so that $L_{t}=1$ for all $t$, since population is constant. Agents born in period $t$ divide their wage $w_{t}$ between consumption when young $c_{0}^{t}$, investment in maintaining the environment $m^{t}$, and savings $k^{t}$ lent to firms for a return rate $r_{t+1}$ to be used in $t+1$ as capital, so that $K_{t+1}=k^{t}$ since population is normalized to 1 . The return to savings $r_{t+1} k^{t}$ is used up as old age consumption. Agents born at date $t$ have preferences over their consumptions when young and old $\left(c_{0}^{t}, c_{1}^{t}\right) \in \mathbb{R}_{+}^{2}$ and the environmental quality when old, $E_{t+1} \in \mathbb{R}$, represented by $u\left(c_{0}^{t}\right)+v\left(c_{1}^{t}\right)+\phi\left(E_{t+1}\right)$ with $u^{\prime}, v^{\prime}, \phi^{\prime}>0, u^{\prime \prime}, v^{\prime \prime}, \phi^{\prime \prime}<0$, and $u^{\prime}(0)=v^{\prime}(0)=+\infty, u^{\prime}(+\infty)=v^{\prime}(+\infty)=0, \phi^{\prime}(+\infty)=0, \phi^{\prime}(-\infty)=+\infty$.

Environmental quality evolves according to

$$
E_{t+1}=(1-b) E_{t}-\alpha F\left(K_{t+1}, L_{t+1}\right)-\beta\left(c_{0}^{t+1}+c_{1}^{t}\right)+\gamma m^{t}
$$

for some $\alpha, \beta, \gamma>0$ and $b \in(0,1]$. That is to say, environmental quality converges autonomously to a natural level normalized to zero at a rate $b$ that measures the speed of reversion to this level. Nonetheless, production and consumption degrade environmental quality by an amount $\alpha F\left(K_{t+1}, 1\right)$ and $\beta\left(c_{0}^{t+1}+c_{1}^{t}\right)$ respectively, while young agents can improve the environmental quality they will enjoy when old by an amount $\gamma m^{t}$ if they devote a portion $m^{t}$ of their labor income to that end. ${ }^{4}$

The life-time utility maximization problem of the representative agent is

\footnotetext{
${ }^{4}$ One can thus interpret environmental quality as including any characteristic that make the environment more apt for human life, like the cleanness of rivers and atmosphere, and the quality of soil or groundwater, etc. It also includes the state of forests, agricultural lands, parks and gardens, which left on their own naturally revert to wilderness, unless subject to regular maintenance.

One can consider the dynamic of environmental quality in a more general form, $E_{t+1}=(1-b) E_{t}-$ $\left(\left[\alpha F\left(K_{t+1}, L_{t+1}\right)\right]^{\frac{1}{\rho}}+\left[\beta\left(c_{0}^{t+1}+c_{1}^{t}\right)-\gamma m^{t}\right]^{\frac{1}{\rho}}\right)^{\rho}$, where $\rho \in(-\infty, 1]$ is the elasticity of substitution between pollution from production and pollution from consumption after maintaining. However, the quantitative results and analysis do not change crucially.
} 


$$
\underset{\substack{c_{0}^{t}, c_{1}^{t}, k^{t}, m^{t} \geq 0 \\ E_{t}, E_{t+1}^{e}}}{\operatorname{Max}} u\left(c_{0}^{t}\right)+v\left(c_{1}^{t}\right)+\phi\left(E_{t+1}^{e}\right)
$$

subject to

$$
\begin{gathered}
c_{0}^{t}+k^{t}+m^{t}=w_{t} \\
c_{1}^{t}=r_{t+1} k^{t} \\
E_{t}=(1-b) E_{t-1}-\alpha F\left(k^{t-1}, 1\right)-\beta\left(c_{0}^{t}+c_{1}^{t-1}\right)+\gamma m^{t-1} \\
E_{t+1}^{e}=(1-b) E_{t}-\alpha F\left(K_{t+1}, 1\right)-\beta\left(c_{0}^{t+1, e}+c_{1}^{t}\right)+\gamma m^{t}
\end{gathered}
$$

where $E_{t+1}^{e}$ is, at $t$, the expected state of environment at $t+1$, given the expected consumption of the next generation young agent $c_{0}^{t+1, e}$ and $E_{t-1}, c_{1}^{t-1}, k^{t-1}, m^{t-1}, w_{t}, r_{t+1}$. Since the representative agent is assumed to be negligible within his own generation, he thinks of the impact of his savings $k^{t}$ on aggregate capital $K_{t+1}$ to be negligible as well, ignoring that actually $K_{t+1}=k^{t}$ at equilibrium. This assumption implies that he does not internalize the impact of the savings decision on environment via production. Notwithstanding, the agent considers the impact of his consumption and maintenance choices not to be negligible. This is meant to capture the idea that agents care actually, not on the global environment, but on the nearby environment on which their consumption and maintenance choices have a direct impact. Anyway given that there is a single representative agent, at equilibrium local and global environment coincide. Since production is not in the hands of the agent (although he supplies the necessary capital through his savings), that he disregards his impact on environment through production is the natural assumption to make.

An interior optimal choice $\left(c_{0}^{t}, c_{1}^{t}, k^{t}, m^{t}, E_{t}, E_{t+1}^{e}\right)$ for agent $t$ is therefore characterized by the first-order conditions

$$
\begin{gathered}
u^{\prime}\left(c_{0}^{t}\right)-[\beta(1-b)+\gamma] \phi^{\prime}\left(E_{t+1}^{e}\right)=0 \\
v^{\prime}\left(c_{1}^{t}\right)-\left[\beta+\frac{\gamma}{r_{t+1}}\right] \phi^{\prime}\left(E_{t+1}^{e}\right)=0 \\
c_{0}^{t}+k^{t}+m^{t}-w_{t}=0 \\
c_{1}^{t}-r_{t+1} k^{t}=0 \\
E_{t}-(1-b) E_{t-1}+\alpha F\left(k^{t-1}, 1\right)+\beta\left(c_{0}^{t}+c_{1}^{t-1}\right)-\gamma m^{t-1}=0 \\
E_{t+1}^{e}-(1-b) E_{t}+\alpha F\left(K_{t+1}, 1\right)+\beta\left(c_{0}^{t+1, e}+c_{1}^{t}\right)-\gamma m^{t}=0
\end{gathered}
$$

to be an implicit function of $E_{t-1}, c_{1}^{t-1}, k^{t-1}, m^{t-1}, w_{t}, r_{t+1}$ and $c_{0}^{t+1, e}$ as long as the Jacobian matrix of the left-hand-side of the system above with respect to $c_{0}^{t}, c_{1}^{t}, k^{t}, m^{t}, E_{t}, E_{t+1}^{e}$ is 
regular at the solution. The existence and regularity of the optimal solution is established in Appendix A1. For these FOCs to be not only necessary but also sufficient for the solution to be a maximum, the second order conditions (SOCs) are shown to hold at equilibrium in Appendix A2.

\section{Competitive equilibria}

The perfect foresight competitive equilibria are characterized by (i) the agent's utility maximization under the budget constraints, with correct expectations, (ii) the firms' profit maximization determining factors' prices, and (iii) the dynamics of environment. Therefore, a competitive equilibrium allocation $\left\{c_{0}^{t}, c_{1}^{t}, k^{t}, m^{t}, E_{t+1}\right\}_{t}$ is solution to the system of equations

$$
\begin{gathered}
u^{\prime}\left(c_{0}^{t}\right)-[\beta(1-b)+\gamma] \phi^{\prime}\left(E_{t+1}\right)=0 \\
v^{\prime}\left(c_{1}^{t}\right)-\left[\beta+\frac{\gamma}{F_{K}\left(k^{t}, 1\right)}\right] \phi^{\prime}\left(E_{t+1}\right)=0 \\
c_{0}^{t}+k^{t}+m^{t}-F_{L}\left(k^{t-1}, 1\right)=0 \\
c_{1}^{t}-F_{K}\left(k^{t}, 1\right) k^{t}=0 \\
E_{t+1}-(1-b) E_{t}+\alpha F\left(k^{t}, 1\right)+\beta\left(c_{0}^{t+1}+c_{1}^{t}\right)-\gamma m^{t}=0
\end{gathered}
$$

Note that the feasibility of the allocation of resources is guaranteed by the agent's budget constraints (16) and (17), since at $t$

$$
c_{0}^{t}+c_{1}^{t-1}+k^{t}+m^{t}=F_{K}\left(k^{t-1}, 1\right) k^{t-1}+F_{L}\left(k^{t-1}, 1\right)=F\left(k^{t-1}, 1\right)
$$

The perfect foresight competitive equilibria of this economy follow a dynamics represented by a first-order difference equation, because of the regularity of the associated Jacobian matrix of the left hand side of the system of equations above with respect to $c_{0}^{t+1}, c_{1}^{t}, k^{t}, m^{t}, E_{t+1}$ (see Appendix A3).

A perfect foresight competitive equilibrium steady state, in particular, is a $\left(c_{0}, c_{1}, k, m, E\right)$ solution to the system of equations

$$
\begin{gathered}
u^{\prime}\left(c_{0}\right)-[\beta(1-b)+\gamma] \phi^{\prime}(E)=0 \\
v^{\prime}\left(c_{1}\right)-\left[\beta+\frac{\gamma}{F_{K}(k, 1)}\right] \phi^{\prime}(E)=0 \\
c_{0}+k+m-F_{L}(k, 1)=0 \\
c_{1}-F_{K}(k, 1) k=0 \\
b E+\alpha F(k, 1)+\beta\left(c_{0}+c_{1}\right)-\gamma m=0
\end{gathered}
$$




\section{The social planner's choice with and without discounting}

In this section, we consider the optimal allocation from the viewpoint of a social planner that allocates resources in order to maximize a weighted sum of the welfare of all current and future generations. The allocation selected by the social planner, which is optimal in the Pareto sense, is a solution to the problem

$$
\underset{\left\{c_{0}^{t}, c_{1}^{t}, k^{t}, m^{t}, E_{t+1}\right\}_{t=0}^{\infty}}{\operatorname{Max}} \sum_{t=0}^{\infty} \frac{1}{(1+R)^{t}}\left[u\left(c_{0}^{t}\right)+v\left(c_{1}^{t}\right)+\phi\left(E_{t+1}\right)\right]
$$

subject to, $\forall t=0,1,2, \ldots$,

$$
\begin{gathered}
c_{0}^{t}+c_{1}^{t-1}+k^{t}+m^{t}=F\left(k^{t-1}, 1\right) \\
E_{t+1}=(1-b) E_{t}-\alpha F\left(k^{t}, 1\right)-\beta\left(c_{0}^{t+1}+c_{1}^{t}\right)+\gamma m^{t}
\end{gathered}
$$

given some initial conditions $c_{1}^{-1}, k^{-1}, E_{0}$, where $0 \leq R$ is the social planner's subjective discount rate. ${ }^{5}$ The first constraint $(20)$ of the problem is the resource constraint of the economy in period $t$ requiring that the total output in that period is split into consumptions of the current young and old, savings for next period's capital, and environmental maintenance. The second constraint (21) is the dynamics of the environmental quality.

The social planner's choice of a steady state is a $\left(\bar{c}_{0}, \bar{c}_{1}, \bar{m}, \bar{k}, \bar{E}\right.$ ) satisfying (see Appendix A4)

$$
\begin{gathered}
u^{\prime}\left(\bar{c}_{0}\right)=(1+R) \frac{\gamma+\beta(1+R)}{b+R} \phi^{\prime}(\bar{E}) \\
v^{\prime}\left(\bar{c}_{1}\right)=\frac{\gamma+\beta(1+R)}{b+R} \phi^{\prime}(\bar{E}) \\
F_{K}(\bar{k}, 1)=\frac{\gamma(1+R)}{\gamma-(1+R) \alpha} \\
\bar{c}_{0}+\bar{c}_{1}+\bar{k}+\bar{m}=F(\bar{k}, 1) \\
b \bar{E}+\alpha F(\bar{k}, 1)+\beta\left(\bar{c}_{0}+\bar{c}_{1}\right)-\gamma \bar{m}=0
\end{gathered}
$$

(the planner's discount rate $R$ cannot be arbitrarily high for the optimal steady state to be characterized as above, specifically $\gamma>(1+R) \alpha$ needs to hold, which requires $\gamma>\alpha$, so that $\left.F_{K}(\bar{k}, 1)>0\right)$. More specifically, in the case of the social planner caring about all generations equally, i.e. $R=0$, the planer's steady state is the so-called golden rule steady state $\left\{c_{0}^{*}, c_{1}^{*}, k^{*}, m^{*}, E^{*}\right\}$ that maximizes the utility of the representative agent and is characterized by being a solution to the system

$$
u^{\prime}\left(c_{0}^{*}\right)=\frac{\gamma+\beta}{b} \phi^{\prime}\left(E^{*}\right)
$$

\footnotetext{
${ }^{5}$ The discount rate $R$ is strictly positive when the social planner cares less about a generation's welfare the further away in the future that generation is, while $R$ equals to zero when she cares about all generations equally, no matter how far in the future they may be.
} 


$$
\begin{gathered}
v^{\prime}\left(c_{1}^{*}\right)=\frac{\gamma+\beta}{b} \phi^{\prime}\left(E^{*}\right) \\
F_{K}\left(k^{*}, 1\right)=\frac{\gamma}{\gamma-\alpha} \\
c_{0}^{*}+c_{1}^{*}+k^{*}+m^{*}=F\left(k^{*}, 1\right) \\
b E^{*}+\alpha F\left(k^{*}, 1\right)+\beta\left(c_{0}^{*}+c_{1}^{*}\right)-\gamma m^{*}=0
\end{gathered}
$$

Note that, from (27) and (28), the marginal utility of consumption of the young agent must equal that of the consumption of the old agent.

Diamond (1965) shows that in the standard OLG model without pollution externalities, a competitive equilibrium steady state whose capital per worker exceeds the golden rule level is dynamically inefficient. In this paper, we consider instead an economy with pollution externalities coming from both production and consumption, in which the environment degrade itself over time, and where the quality of the environment can be improved through maintenance. It turns out that, as in Diamond (1965), the golden rule capital ratio of this economy with pollution externalities is still the highest level of capital ratio that is dynamically efficient. ${ }^{6}$

Proposition 1: In a Diamond (1965) overlapping generations economy with consumption and production pollution, for an efficient enough cleaning technology, compared to the marginal polluting impact of production (specifically, for $\gamma>\alpha$ in the model), the golden rule capital ratio (i.e. the planner's steady state choice without discounting) is the highest dynamically efficient capital ratio.

Proof: Since $F_{K K}(k, 1)<0$ for all $k$, the planner's optimal capital ratio $\bar{k}$ is implicitly defined to be a differentiable function $\bar{k}(R)$ of $R$ by the condition

$$
F_{K}(\bar{k}, 1)=\frac{\gamma(1+R)}{\gamma-(1+R) \alpha}
$$

whose derivative, by the implicit function theorem, is

$$
\bar{k}^{\prime}(R)=\frac{1}{F_{K K}(\bar{k}(R), 1)}\left(\frac{\gamma}{\gamma-(1+R) \alpha}\right)^{2}<0
$$

So, $\bar{k}$ is decreasing in $R$. Hence, $\bar{k}(R)$ is maximal when $R=0$, which is corresponds to the golden rule level of capital $k^{*}$.

Proposition 1 shows that any steady state capital ratio exceeding $k^{*}$ is dynamically inefficient. From $(29)$ the golden rule capital ratio $k^{*}$ is decreasing in the production pollution

\footnotetext{
${ }^{6}$ In a different framework and when pollution externalities are large enough, Gutiérrez (2008) has shown the existence of dynamically efficient competitive equilibrium steady state capital ratios that exceed the golden rule capital ratio. Specifically, when (i) pollution externalities come only from production; (ii) environment recovers itself at a constant rate; (iii) no resource is devoted to maintaining the environment; and (iv) the pollution externality decreases the utility of the agents only indirectly by requiring each agent to pay for extra health costs in the old age, Gutiérrez (2008) shows the existence of a "super golden rule" level of capital ratio (beyond the golden rule level) such that any stationary capital ratio exceeding this level is necessarily dynamically inefficient.
} 
parameter $\alpha$. It is, however, increasing in the environment maintaining technology $\gamma$. Hence, the more polluting is production, the smaller the range of steady state allocations that are dynamically efficient for some discount factor $R$. Similarly, the more effective is the environment maintainance technology, the bigger the range of steady state allocations that are dynamically efficient for some discount factor $R$.

\section{Policy implementation of the planner's optimal steady state}

In this section, we provide tax and transfer policies allowing to implement the planner's optimal steady state. Ono (1996) and Gutiérrez (2008) introduced also tax and transfer schemes to decentralize the golden rule steady state in the context of the pollution externalities they consider (from consumption and production only, respectively). However, their schemes uphold the golden rule once the economy is already at that steady state. In this section we provide instead policies that lead the economy towards the social planer's first best steady state and will keep it there once reached. The policies fulfill this in two stages. In the first stage (in the period $t-1$ ), taxes and transfers are set in order to make the agent born in period $t-1$ choose $c_{0}^{t-1}=c_{0}^{*}, c_{1}^{t-1}=c_{1}^{*}, k^{t-1}=k^{*}$ and $E_{t}^{e}=E^{*}$ (but not $m^{t-1}=m^{*}$ or $\left.E_{t-1}=E^{*}\right)$. For the sake of avoiding unnecessary cumbersome notation the argument is presented for the case $R=0$, although it can be rewritten for any $R \geq 0$ ). Then, in the second stage, taxes and transfers are reset to uphold the planner's steady state from period $t$ onward. The first scheme based on the taxation of consumption is presented next in detail. The subsequent schemes work analogously.

\subsection{Taxes on consumptions}

As in Ono (1996) we consider first taxes on consumption along with lump-sum taxes and transfers. Letting $\tau_{0}^{t}$ and $\tau_{1}^{t}$ be the tax rate on agent $t$ 's consumption when young and old respectively, $T_{0}^{t}$ a lump-sum tax (if positive) levied on agent $t^{\prime}$ s income when young, and $T_{1}^{t}$ a lump-sum transfer (if positive) to the same agent when old at date $t+1$, the problem of agent $t$ is then

$$
\underset{\substack{c_{0}^{t}, c_{1}^{t}, k^{t}, m^{t} \geq 0 \\ E_{t}, E_{t+1}^{e}}}{\operatorname{Max}} u\left(c_{0}^{t}\right)+v\left(c_{1}^{t}\right)+\phi\left(E_{t+1}^{e}\right)
$$

subject to

$$
\begin{gathered}
\left(1+\tau_{0}^{t}\right) c_{0}^{t}+k^{t}+m^{t}=w_{t}-T_{0}^{t} \\
\left(1+\tau_{1}^{t}\right) c_{1}^{t}=r_{t+1} k^{t}+T_{1}^{t} \\
E_{t}=(1-b) E_{t-1}-\alpha F\left(k^{t-1}, 1\right)-\beta\left(c_{0}^{t}+c_{1}^{t-1}\right)+\gamma m^{t-1} \\
E_{t+1}^{e}=(1-b) E_{t}-\alpha F\left(K_{t+1}, 1\right)-\beta\left(c_{0}^{t+1, e}+c_{1}^{t}\right)+\gamma m^{t}
\end{gathered}
$$

given $E_{t-1}, c_{1}^{t-1}, k^{t-1}, m^{t-1}, w_{t-1}, c_{0}^{t+1, e}$ and $r_{t+1}$. Note again that in equation (37), the agent, being negligible within his generation, ignores the fact that $K_{t+1}=k^{t}$ and hence is 
unable to internalize the effect of the savings decisions on environment through the aggregate output.

Proposition 2: In a Diamond (1965) overlapping generations economy with pollution from both consumption and production, the planner's steady state can be implemented at any given period $t$ by the following period-by-period balanced-budget policy:

announce at $t-1$ that the following consumption tax rates and lump-sum transfers will apply,

(1) to generation born at $t-1$

$$
\begin{gathered}
\tau_{0}^{t-1}=\frac{\gamma+\beta-[\gamma+\beta(1-b)] b}{\gamma b} \\
\tau_{1}^{t-1}=\frac{\gamma+\beta(1-b)}{(\gamma-\alpha) b} \\
T_{0}^{t-1}=\frac{1}{A}\left(\begin{array}{c}
\gamma \\
1-b \\
-1
\end{array}\right)\left(\begin{array}{c}
F_{L}\left(k^{t-2}, 1\right)-\left(1+\tau_{0}\right) c_{0}^{*}-k^{*} \\
(1-b) E_{t-2}-\alpha F\left(k^{t-2}, 1\right)-\beta\left(\left(1+\tau_{0}\right) c_{0}^{*}+c_{1}^{t-2}\right)+\gamma m^{t-2} \\
E^{*}+\alpha F\left(k^{*}, 1\right)+\beta\left(c_{0}^{*}+c_{1}^{*}\right)
\end{array}\right) \\
T_{1}^{t-1}=\left(1+\tau_{1}\right) c_{1}^{*}-F_{K}\left(k^{*}, 1\right) k^{*}
\end{gathered}
$$

where $A=\gamma+\beta(1-b)$

(2) to generation born from $t$ onwards

$$
\begin{gathered}
\tau_{0}=\frac{\gamma+\beta-[\gamma+\beta(1-b)] b}{\gamma b} \\
\tau_{1}=\frac{\gamma+\beta(1-b)}{(\gamma-\alpha) b} \\
T_{0}=F_{L}\left(k^{*}, 1\right)-\left(1+\tau_{0}\right) c_{0}^{*}-k^{*}-m^{*} \\
T_{1}=\left(1+\tau_{1}\right) c_{1}^{*}-F_{K}\left(k^{*}, 1\right) k^{*}
\end{gathered}
$$

Proof: Note first that, since a competitive equilibrium steady state under a period-byperiod balanced-budget stationary policy of consumption tax rates $\tau_{0}, \tau_{1}$ and lump-sum transfers $T_{0}, T_{1}$ is characterized by

$$
\begin{gathered}
u^{\prime}\left(c_{0}\right)=\left[\beta(1-b)+\gamma\left(1+\tau_{0}\right)\right] \phi^{\prime}(E) \\
u^{\prime}\left(c_{0}\right)=\left[\beta+\frac{\gamma}{F_{K}(k, 1)}\left(1+\tau_{1}\right)\right] \phi^{\prime}(E) \\
\left(1+\tau_{0}\right) c_{0}+k+m=F_{L}(k, 1)-T_{0} \\
\left(1+\tau_{1}\right) c_{1}=F_{K}(k, 1) k+T_{1}
\end{gathered}
$$




$$
E=(1-b) E-\alpha F(k, 1)-\beta\left(c_{0}+c_{1}\right)+\gamma m
$$

and

$$
\tau_{0} c_{0}+\tau_{1} c_{1}+T_{0}=T_{1}
$$

and since the planner's steady state is characterized by

$$
\begin{gathered}
u^{\prime}\left(c_{0}^{*}\right)=\frac{\gamma+\beta}{b} \phi^{\prime}\left(E^{*}\right) \\
v^{\prime}\left(c_{1}^{*}\right)=\frac{\gamma+\beta}{b} \phi^{\prime}\left(E^{*}\right) \\
F_{K}\left(k^{*}, 1\right)=\frac{\gamma}{\gamma-\alpha} \\
c_{0}^{*}+c_{1}^{*}+k^{*}+m^{*}=F\left(k^{*}, 1\right) \\
E^{*}=(1-b) E^{*}-\alpha F\left(k^{*}, 1\right)-\beta\left(c_{0}^{*}+c_{1}^{*}\right)+\gamma m^{*}
\end{gathered}
$$

then for the stationary competitive equilibrium under $\tau_{0}, \tau_{1}, T_{0}, T_{1}$ to be the planner's steady state it is necessary and sufficient that

$$
\begin{gathered}
\beta(1-b)+\gamma\left(1+\tau_{0}\right)=\frac{\gamma+\beta}{b} \\
\beta+\frac{\gamma}{F_{K}\left(k^{*}, 1\right)}\left(1+\tau_{1}\right)=\frac{\gamma+\beta}{b} \\
\left(1+\tau_{0}\right) c_{0}^{*}+k^{*}+m^{*}=F_{L}\left(k^{*}, 1\right)-T_{0} \\
\left(1+\tau_{1}\right) c_{1}^{*}=F_{K}\left(k^{*}, 1\right) k^{*}+T_{1}
\end{gathered}
$$

i.e. that

$$
\begin{gathered}
\tau_{0}=\frac{\gamma+\beta-[\gamma+\beta(1-b)] b}{\gamma b} \\
\tau_{1}=\frac{\gamma+\beta(1-b)}{(\gamma-\alpha) b} \\
T_{0}=F_{L}\left(k^{*}, 1\right)-\left(1+\tau_{0}\right) c_{0}^{*}-k^{*}-m^{*} \\
T_{1}=\left(1+\tau_{1}\right) c_{1}^{*}-F_{K}\left(k^{*}, 1\right) k^{*}
\end{gathered}
$$

In other words, such a policy supports the planner's steady state once the economy is there. There is then the additional problem of moving the economy to the planner's steady state. 
To address this additional problem, it should be noticed that the choice by agent $t$ of $c_{0}^{t}, c_{1}^{t}, k^{t}, m^{t}, E_{t}, E_{t+1}^{e}$ depends on past decisions, in particular on $k^{t-1}$ through $w_{t}=$ $F_{L}\left(k^{t-1}, 1\right)$, and on $c_{1}^{t-1}, m^{t-1}, E_{t-1}$ through the environment dynamics. We shall show next that there exists a balanced-budget policy towards generation $t-1$ that makes it choose $c_{0}^{*}, c_{1}^{*}, k^{*}$ and $E_{t}^{e}=E^{*}$ (but not $m^{*}$ or $E_{t-1}=E^{*}$ ), and another policy towards generation $t$, namely the policy above, that makes it choose $c_{0}^{*}, c_{1}^{*}, k^{*}$ and $E_{t+1}^{e}=E^{*}$ as well as $m^{*}$ and $E_{t}=E^{*}$. Once there the same policy keeps the economy at the planner's steady state.

In effect, agent $t-1$ 's choice at a perfect foresight equilibrium is characterized by the conditions

$$
\begin{gathered}
u^{\prime}\left(c_{0}^{t-1}\right)=\left[\beta(1-b)+\gamma\left(1+\tau_{0}\right)\right] \phi^{\prime}\left(E_{t}\right) \\
v^{\prime}\left(c_{1}^{t-1}\right)=\left[\beta+\frac{\gamma}{F_{K}\left(k^{t-1}, 1\right)}\left(1+\tau_{1}\right)\right] \phi^{\prime}\left(E_{t}\right) \\
\left(1+\tau_{0}\right) c_{0}^{t-1}+k^{t-1}+m^{t-1}=F_{L}\left(k^{t-2}, 1\right)-T_{0}^{t-1} \\
\left(1+\tau_{1}\right) c_{1}^{t-1}=F_{K}\left(k^{t-1}, 1\right) k^{t-1}+T_{1}^{t-1} \\
E_{t-1}=(1-b) E_{t-2}-\alpha F\left(k^{t-2}, 1\right)-\beta\left(c_{0}^{t-1}+c_{1}^{t-2}+T_{1}^{t-2}\right)+\gamma m^{t-2} \\
E_{t}=(1-b) E_{t-1}-\alpha F\left(k^{t-1}, 1\right)-\beta\left(c_{0}^{t}+c_{1}^{t-1}\right)+\gamma m^{t-1}
\end{gathered}
$$

given past decisions $c_{1}^{t-2}, k^{t-2}, m^{t-2}, E_{t-2}$ and $c_{0}^{t}$. Note that, for the government's budget to be balanced at $t-1$, generation $t-2$ receives as a transfer $T_{1}^{t-2}$ all the taxes raised at $t-1$, i.e.

$$
T_{1}^{t-2}=\tau_{0} c_{0}^{t-1}+T_{0}^{t-1}
$$

Keeping this in mind, it turns out that there exist transfers $T_{0}^{t-1}, T_{1}^{t-1}$ such that under $\tau_{0}, \tau_{1}$ above generation $t-1$ chooses $c_{0}^{*}, c_{1}^{*}, k^{*}$ and $E_{t}^{e}=E^{*}$. In effect, there is a solution in $c_{0}^{t-1}, T_{0}^{t-1}, T_{1}^{t-1}, m^{t-1}, E_{t-1}, E_{t}$ to the system above with $c^{t-1}=c_{1}^{*}$ and $k^{t-1}=k^{*}$, i.e. a solution to

$$
\begin{gathered}
u^{\prime}\left(c_{0}^{t-1}\right)=\left[\beta(1-b)+\gamma\left(1+\tau_{0}\right)\right] \phi^{\prime}\left(E_{t}\right) \\
v^{\prime}\left(c_{1}^{*}\right)=\left[\beta+\frac{\gamma}{F_{K}\left(k^{*}, 1\right)}\left(1+\tau_{1}\right)\right] \phi^{\prime}\left(E_{t}\right) \\
\left(1+\tau_{0}\right) c_{0}^{t-1}+k^{*}+m^{t-1}=F_{L}\left(k^{t-2}, 1\right)-T_{0}^{t-1} \\
\left(1+\tau_{1}\right) c_{1}^{*}=F_{K}\left(k^{*}, 1\right) k^{*}+T_{1}^{t-1} \\
E_{t-1}=(1-b) E_{t-2}-\alpha F\left(k^{t-2}, 1\right)-\beta\left(\left(1+\tau_{0}\right) c_{0}^{t-1}+c_{1}^{t-2}+T_{0}^{t-1}\right)+\gamma m^{t-2}
\end{gathered}
$$




$$
E_{t}=(1-b) E_{t-1}-\alpha F\left(k^{*}, 1\right)-\beta\left(c_{0}^{t}+c_{1}^{*}\right)+\gamma m^{t-1}
$$

(where $c_{1}^{t-1}$ and $k^{t-1}$ have been fixed at the levels $c_{1}^{*}$ and $k^{*}$ respectively) since, given the conditions characterizing the planner's steady state, from the second equation necessarily $E_{t}=E^{*}$, which in turn implies, from the first equation, that $c_{0}^{t-1}=c_{0}^{*}$. The fourth equation directly determines

$$
T_{1}^{t-1}=\left(1+\tau_{1}\right) c_{1}^{*}-F_{K}\left(k^{*}, 1\right) k^{*}
$$

and the three other equations constitute the following regular linear system in $m^{t-1}, T_{0}^{t-1}$, and $E_{t-1}$

$$
\begin{gathered}
T_{0}^{t-1}+m^{t-1}=F_{L}\left(k^{t-2}, 1\right)-\left(1+\tau_{0}\right) c_{0}^{*}-k^{*} \\
E_{t-1}+\beta T_{0}^{t-1}=(1-b) E_{t-2}-\alpha F\left(k^{t-2}, 1\right)-\beta\left(\left(1+\tau_{0}\right) c_{0}^{*}+c_{1}^{t-2}\right)+\gamma m^{t-2} \\
(1-b) E_{t-1}+\gamma m^{t-1}=E_{t}+\alpha F\left(k^{*}, 1\right)+\beta\left(c_{0}^{t}+c_{1}^{*}\right)
\end{gathered}
$$

with solution

$$
\begin{aligned}
\left(\begin{array}{c}
m^{t-1} \\
T_{0}^{t-1} \\
E_{t-1}
\end{array}\right)= & \frac{1}{A}\left(\begin{array}{ccc}
(1-b) \beta & b-1 & 1 \\
\gamma & 1-b & -1 \\
-\gamma \beta & \gamma & \beta
\end{array}\right) \\
& \cdot\left(\begin{array}{c}
(1-b) E_{t-2}-\alpha F\left(k^{t-2}, 1\right)-\beta\left(\left(1+\tau_{0}\right) c_{0}^{*}+c_{1}^{t-2}\right)+\gamma m^{t-2} \\
E_{t}+\alpha F\left(k^{*}, 1\right)+\beta\left(c_{0}^{t}+c_{1}^{*}\right)
\end{array}\right)
\end{aligned}
$$

where $A=\gamma+\beta(1-b)$ is the determinant of the matrix of coefficients.

Thus, under the following policy of consumption tax rates and lump-sum transfers

$$
\begin{gathered}
\tau_{0}^{t-1}=\frac{\gamma+\beta-[\gamma+\beta(1-b)] b}{\gamma b} \\
\tau_{1}^{t-1}=\frac{\gamma+\beta(1-b)}{(\gamma-\alpha) b} \\
T_{0}^{t-1}=\frac{1}{A}\left(\begin{array}{c}
\gamma \\
1-b \\
-1
\end{array}\right)^{t}\left(\begin{array}{c}
F_{L}\left(k^{t-2}, 1\right)-\left(1+\tau_{0}\right) c_{0}^{*}-k^{*} \\
(1-b) E_{t-2}-\alpha F\left(k^{t-2}, 1\right)-\beta\left(\left(1+\tau_{0}\right) c_{0}^{*}+c_{1}^{t-2}\right)+\gamma m^{t-2} \\
E_{t}+\alpha F\left(k^{*}, 1\right)+\beta\left(c_{0}^{t}+c_{1}^{*}\right)
\end{array}\right) \\
T_{1}^{t-1}=\left(1+\tau_{1}\right) c_{1}^{*}-F_{K}\left(k^{*}, 1\right) k^{*}
\end{gathered}
$$

generation $t-1$ makes at equilibrium the choices

$$
\begin{aligned}
& c_{0}^{t-1}=c_{0}^{*} \\
& c_{1}^{t-1}=c_{1}^{*} \\
& k^{t-1}=k^{*}
\end{aligned}
$$




$$
\begin{gathered}
m^{t-1}=\frac{1}{A}\left(\begin{array}{c}
(1-b) \beta \\
b-1 \\
1
\end{array}\right)^{t}\left(\begin{array}{c}
F_{L}\left(k^{t-2}, 1\right)-\left(1+\tau_{0}\right) c_{0}^{*}-k^{*} \\
(1-b) E_{t-2}-\alpha F\left(k^{t-2}, 1\right)-\beta\left(\left(1+\tau_{0}\right) c_{0}^{*}+c_{1}^{t-2}\right)+\gamma m^{t-2} \\
E_{t}+\alpha F\left(k^{*}, 1\right)+\beta\left(c_{0}^{t}+c_{1}^{*}\right)
\end{array}\right) \\
E_{t-1}=\frac{1}{A}\left(\begin{array}{c}
-\gamma \beta \\
\gamma \\
\beta
\end{array}\right)\left(\begin{array}{c}
F_{L}\left(k^{t-2}, 1\right)-\left(1+\tau_{0}\right) c_{0}^{*}-k^{*} \\
(1-b) E_{t-2}-\alpha F\left(k^{t-2}, 1\right)-\beta\left(\left(1+\tau_{0}\right) c_{0}^{*}+c_{1}^{t-2}\right)+\gamma m^{t-2} \\
E_{t}+\alpha F\left(k^{*}, 1\right)+\beta\left(c_{0}^{t}+c_{1}^{*}\right) \\
E_{t}=E^{*}
\end{array}\right)
\end{gathered}
$$

Note that the policy above depends on elements known at the time $t-1$ of announcing it, except for the transfer $T_{0}^{t-1}$, which depends as well on the expected (and, at a perfect foresight equilibrium, the actual) first-period consumption of generation $t, c_{0}^{t}$. The choice of $m^{t-1}$ and $E_{t-1}$ by generation $t-1$ depends on it accordingly. Nevertheless, under the announcement at $t-1$ that the same consumption tax rates will be applied to generation $t$ as well, along with the stationary balanced-budget transfers implementing the planner's steady state, i.e. under the policy

$$
\begin{gathered}
\tau_{0}^{t}=\frac{\gamma+\beta-[\gamma+\beta(1-b)] b}{\gamma b} \\
\tau_{1}^{t}=\frac{\gamma+\beta(1-b)}{(\gamma-\alpha) b} \\
T_{0}=F_{L}\left(k^{*}, 1\right)-\left(1+\tau_{0}\right) c_{0}^{*}-k^{*}-m^{*} \\
T_{1}=\left(1+\tau_{1}\right) c_{1}^{*}-F_{K}\left(k^{*}, 1\right) k^{*}
\end{gathered}
$$

it is perfectly foreseen at $t-1$ that at equilibrium $c_{0}^{t}=c_{0}^{*}$. More specifically, under this policy generation $t^{\prime}$ s choice is $c_{0}^{*}, c_{1}^{*}, k^{*}, m^{*}, E_{t}=E^{*}$ and $E_{t+1}^{e}=E^{*}$, since this choice solves

$$
\begin{gathered}
u^{\prime}\left(c_{0}^{t}\right)=\left[\beta(1-b)+\gamma\left(1+\tau_{0}\right)\right] \phi^{\prime}\left(E_{t+1}^{e}\right) \\
v^{\prime}\left(c_{1}^{t}\right)=\left[\beta+\frac{\gamma}{F_{K}\left(k^{t}, 1\right)}\left(1+\tau_{1}\right)\right] \phi^{\prime}\left(E_{t+1}^{e}\right) \\
\left(1+\tau_{0}\right) c_{0}^{t}+k^{t}+m^{t}=F_{L}\left(k^{*}, 1\right)-T_{0}^{t} \\
\left(1+\tau_{1}\right) c_{1}^{t}=F_{K}\left(k^{t}, 1\right) k^{t}+T_{1}^{t} \\
E_{t}=(1-b) E_{t-1}-\alpha F\left(k^{*}, 1\right)-\beta\left(c_{0}^{t}+c_{1}^{*}\right)+\gamma m^{t-1} \\
E_{t+1}^{e}=(1-b) E_{t}-\alpha F\left(k^{t}, 1\right)-\beta\left(c_{0}^{t+1, e}+c_{1}^{t}\right)+\gamma m^{t}
\end{gathered}
$$

given that $E_{t+1}^{e}, c_{0}^{t+1, e}$ are perfectly foreseen to be $E^{*}, c_{0}^{*}$ when the policy is left unchanged for all generations from generation $t$ onwards, and the next-to-last equation is guaranteed to be satisfied from the choices of $E_{t-1}$ and $m^{t-1}$ by generation $t-1$ at $t-1$ (it is the last equation in generation $t-1$ 's system). 
Finally, note that at period $t$ the policy is balanced as well (at $t-1$ and from $t+1$ onwards it is so by construction), i.e.

$$
T_{1}^{t-1}=\tau_{0} c_{0}^{t}+\tau_{1} c_{1}^{t-1}+T_{0}^{t}
$$

that is to say

$$
\left(1+\tau_{1}\right) c_{1}^{*}-F_{K}\left(k^{*}, 1\right) k^{*}=\tau_{0} c_{0}^{*}+\tau_{1} c_{1}^{*}+F_{L}\left(k^{*}, 1\right)-\left(1+\tau_{0}\right) c_{0}^{*}-k^{*}-m^{*}
$$

which boils down to

$$
c_{0}^{*}+c_{1}^{*}+k^{*}+m^{*}=F_{K}\left(k^{*}, 1\right) k^{*}+F_{L}\left(k^{*}, 1\right)
$$

which is guaranteed by the feasibility of the planers' steady state.

\subsection{Taxes on consumptions and capital income}

In the section 5.1, we introduced taxes on consumptions in which the tax rates differ between consumptions of the old and the young. In reality, however, this tax scheme seems to be difficult to apply because it discriminates between young and old agents. In order to avoid the discrimination, a unique rate of consumption tax $\tau^{t}$ should be applied. Beside that, a capital income tax $\tau_{k}^{t}$ and a system of lump-sum tax $T_{0}^{t}$ (if positive) and lump-sum transfer $T_{1}^{t}$ (if positive), levied on agent $t$ 's incomes, are introduced to show that the best steady state allocation can be achieved. The problem of agent $t$ under the tax policy is then

$$
\underset{\substack{c_{0}^{t}, c_{1}^{t}, k^{t}, m^{t} \geq 0 \\ E_{t}, E_{t+1}^{e}}}{\operatorname{Max}} u\left(c_{0}^{t}\right)+v\left(c_{1}^{t}\right)+\phi\left(E_{t+1}^{e}\right)
$$

subject to

$$
\begin{gathered}
\left(1+\tau^{t}\right) c_{0}^{t}+k^{t}+m^{t}=w_{t}-T_{0}^{t} \\
\left(1+\tau^{t}\right) c_{1}^{t}=\left(1-\tau_{k}^{t}\right) r_{t+1} k^{t}+T_{1}^{t} \\
E_{t}=(1-b) E_{t-1}-\alpha F\left(k^{t-1}, 1\right)-\beta\left(c_{0}^{t}+c_{1}^{t-1}\right)+\gamma m^{t-1} \\
E_{t+1}^{e}=(1-b) E_{t}-\alpha F\left(K_{t+1}, 1\right)-\beta\left(c_{0}^{t+1, e}+c_{1}^{t}\right)+\gamma m^{t}
\end{gathered}
$$

given $E_{t-1}, c_{1}^{t-1}, k^{t-1}, m^{t-1}, w_{t}, c_{0}^{t+1, e}$ and $r_{t+1}$. Note again that in equation (42), the agent, being negligible within his generation, ignores the fact that $K_{t+1}=k^{t}$ and hence is unable to internalize the effect of the savings decisions on environment through the aggregate output.

Proposition 3: In a Diamond (1965) overlapping generations economy with pollution from both consumption and production, the planner's steady state can be implemented at any given period $t$ by the following period-by-period balanced-budget policy:

announce at $t-1$ that the following consumption tax rate, capital income tax rate and lump-sum transfers will apply,

(1) to generation born at $t-1$ 


$$
\begin{gathered}
\tau^{t-1}=\frac{\gamma+\beta-[\gamma+\beta(1-b)] b}{\gamma b} \\
\tau_{k}^{t-1}=\frac{\alpha(\gamma+\beta)-\beta b^{2}(\gamma-\alpha)+\alpha \beta b}{\gamma[\gamma+\beta(1-b)]} \\
T_{0}^{t-1}=\frac{1}{A}\left(\begin{array}{c}
\gamma \\
1-b \\
-1
\end{array}\right)\left(\begin{array}{c}
(1-b) E_{t-2}-\alpha F\left(k^{t-2}, 1\right)-\beta\left((1+\tau) c_{0}^{*}+c_{1}^{t-2}\right)+\gamma m^{t-2} \\
E^{*}+\alpha F\left(k^{*}, 1\right)+\beta\left(c_{0}^{*}+c_{1}^{*}\right)
\end{array}\right) \\
T_{1}^{t-1}=(1+\tau) c_{1}^{*}-\left(1-\tau_{k}\right) F_{K}\left(k^{*}, 1\right) k^{*}
\end{gathered}
$$

where $A=\gamma+\beta(1-b)$

(2) to all generations born from period $t$ onwards

$$
\begin{gathered}
\tau=\frac{\gamma+\beta-[\gamma+\beta(1-b)] b}{\gamma b} \\
\tau_{k}=\frac{\alpha(\gamma+\beta)-\beta b^{2}(\gamma-\alpha)+\alpha \beta b}{\gamma[\gamma+\beta(1-b)]} \\
T_{0}=F_{L}\left(k^{*}, 1\right)-(1+\tau) c_{0}^{*}-k^{*}-m^{*} \\
T_{1}=(1+\tau) c_{1}^{*}-\left(1-\tau_{k}\right) F_{K}\left(k^{*}, 1\right) k^{*}
\end{gathered}
$$

Proof: The proof for this proposition is similar to the proof for proposition 2.

\subsection{Taxes on consumptions and production}

We still keep the non-discriminatory tax rate $\tau^{t}$ on consumptions and the system of lumpsum tax $T_{0}^{t}$ (if positive) and lump-sum transfer $T_{1}^{t}$ (if positive). However, we now introduce a Pigouvian tax on production instead of tax on capital income. In any period $t$, let $\tau_{p}^{t}$ be the tax paid by firms per one unit of output produced in period $t$. We will design taxes and transfers policy ensuring the government's budget to be balanced and achieving the planner's steady state through competitive markets.

Under the production tax, the problem that the firm must solve in period $t$ is

$$
\underset{K_{t}}{\operatorname{Max}}\left(1-\tau_{p}^{t}\right) F\left(K_{t}, 1\right)-r_{t} K_{t}-w_{t}
$$

The returns to capital and labor are at equilibrium respectively

$$
\begin{aligned}
& r_{t}=\left(1-\tau_{p}^{t}\right) F_{K}\left(k^{t-1}, 1\right) \\
& w_{t}=\left(1-\tau_{p}^{t}\right) F_{L}\left(k^{t-1}, 1\right)
\end{aligned}
$$

Under the taxes and transfers policy, the agent $t$ 's problem is 


$$
\underset{\substack{c_{0}^{t}, c_{1}^{t}, k^{t}, m^{t} \geq 0 \\ E_{t}, E_{t+1}^{e}}}{\operatorname{Max}} u\left(c_{0}^{t}\right)+v\left(c_{1}^{t}\right)+\phi\left(E_{t+1}^{e}\right)
$$

subject to

$$
\begin{gathered}
\left(1+\tau^{t}\right) c_{0}^{t}+k^{t}+m^{t}=w_{t}-T_{0}^{t} \\
\left(1+\tau^{t}\right) c_{1}^{t}=r_{t+1} k^{t}+T_{1}^{t} \\
E_{t}=(1-b) E_{t-1}-\alpha F\left(k^{t-1}, 1\right)-\beta\left(c_{0}^{t}+c_{1}^{t-1}\right)+\gamma m^{t-1} \\
E_{t+1}^{e}=(1-b) E_{t}-\alpha F\left(K_{t+1}, 1\right)-\beta\left(c_{0}^{t+1, e}+c_{1}^{t}\right)+\gamma m^{t-1}
\end{gathered}
$$

given $E_{t-1}, c_{1}^{t-1}, k^{t-1}, m^{t-1}, w_{t}, c_{0}^{t+1, e}$ and $r_{t+1}$. Note again that in equation (50), the agent, being negligible within his generation, ignores the fact that $K_{t+1}=k^{t}$ and hence is unable to internalize the effect of the savings decisions on environment through the aggregate output.

Proposition 4: In a Diamond (1965) overlapping generations economy with pollution from both consumption and production, the planner's steady state can be implemented at any given period $t$ by the following period-by-period balanced-budget policy:

announce at $t-1$ that the following consumption tax rate, production tax rates and lump-sum transfers will apply,

(1) to generation born at $t-1$

$$
\begin{gathered}
\tau^{t-1}=\frac{\gamma+\beta-[\gamma+\beta(1-b)] b}{\gamma b} \\
\tau_{p}^{t}=\frac{\alpha(\gamma+\beta)-\beta b^{2}(\gamma-\alpha)+\alpha \beta b}{\gamma[\gamma+\beta(1-b)]} \\
T_{0}^{t-1}=\frac{1}{A}\left(\begin{array}{c}
\gamma \\
1-b \\
-1
\end{array}\right)\left(\begin{array}{c}
(1-b) E_{t-2}-\alpha F\left(k^{t-2}, 1\right)-\beta\left((1+\tau) c_{0}^{*}+c_{1}^{t-2}\right)+\gamma m^{t-2} \\
E^{*}+\alpha F\left(k^{*}, 1\right)+\beta\left(c_{0}^{*}+c_{1}^{*}\right)
\end{array}\right) \\
T_{1}^{t-1}=(1+\tau) c_{1}^{*}-\left(1-\tau_{k}\right) F_{K}\left(k^{*}, 1\right) k^{*}
\end{gathered}
$$

where $A=\gamma+\beta(1-b)$

(2) to all generations born from period $t$ onwards

$$
\begin{gathered}
\tau=\frac{\gamma+\beta-[\gamma+\beta(1-b)] b}{\gamma b} \\
\tau_{p}=\frac{\alpha(\gamma+\beta)-\beta b^{2}(\gamma-\alpha)+\alpha \beta b}{\gamma[\gamma+\beta(1-b)]} \\
T_{0}=\left(1-\tau_{p}\right) F_{L}\left(k^{*}, 1\right)-(1+\tau) c_{0}^{*}-k^{*}-m^{*}
\end{gathered}
$$




$$
T_{1}=(1+\tau) c_{1}^{*}-\left(1-\tau_{p}\right) F_{K}\left(k^{*}, 1\right) k^{*}
$$

Proof: The proof for this proposition is similar to the proof for proposition 2.

\subsection{Taxes on consumption, production and labor income}

We now modify the tax and transfer policy introduced in section 5.3 by using the labor income tax rate $\tau_{w}^{t}$ to replace the lump-sum tax $T_{0}^{t}$. All other things are kept the same as in the section 5.3. Under this policy, the agent t's problem is

$$
\underset{\substack{c_{0}^{t}, c_{c}^{t}, k^{t}, m^{t} \geq 0 \\ E_{t}, E_{t+1}^{e}}}{\operatorname{Max}} u\left(c_{0}^{t}\right)+v\left(c_{1}^{t}\right)+\phi\left(E_{t+1}^{e}\right)
$$

subject to

$$
\begin{gathered}
\left(1+\tau^{t}\right) c_{0}^{t}+k^{t}+m^{t}=\left(1-\tau_{w}^{t}\right) w_{t} \\
\left(1+\tau^{t}\right) c_{1}^{t}=r_{t+1} k^{t}+T_{1}^{t} \\
E_{t}=(1-b) E_{t}-\alpha F\left(k^{t-1}, 1\right)-\beta\left(c_{0}^{t}+c_{1}^{t-1}\right)+\gamma m^{t-1} \\
E_{t+1}^{e}=(1-b) E_{t}-\alpha F\left(K_{t+1}, 1\right)-\beta\left(c_{0}^{t+1, e}+c_{1}^{t}\right)+\gamma m^{t}
\end{gathered}
$$

given $E_{t-1}, c_{1}^{t-1}, k^{t-1}, m^{t-1}, w_{t}, c_{0}^{t+1, e}$ and $r_{t+1}$. Note again that in equation (55), the agent, being negligible within his generation, ignores the fact that $K_{t+1}=k^{t}$ and hence is unable to internalize the effect of the savings decisions on environment through the aggregate output.

Proposition 5: In a Diamond (1965) overlapping generations economy with pollution from both consumption and production, the planner's steady state can be implemented at any given period $t$ by the following period-by-period balanced-budget policy:

announce at $t-1$ that the following consumption tax rate, production tax rate, labor tax rate ans lump-sum transfer will apply,

(1) to generation born at $t-1$

$$
\begin{gathered}
\tau^{t-1}=\frac{\gamma+\beta-[\gamma+\beta(1-b)] b}{\gamma b} \\
\tau_{p}^{t}=\frac{\alpha(\gamma+\beta)-\beta b^{2}(\gamma-\alpha)+\alpha \beta b}{\gamma[\gamma+\beta(1-b)]} \\
\tau_{w}^{t-1}=\frac{1}{B}\left(\begin{array}{c}
\gamma \\
1-b \\
-1
\end{array}\right)^{t}\left(\begin{array}{c}
F_{L}\left(k^{t-2}, 1\right)-(1+\tau) c_{0}^{*}-k^{*} \\
(1-b) E_{t-2}-\alpha F\left(k^{t-2}, 1\right)-\beta\left((1+\tau) c_{0}^{*}+c_{1}^{t-2}\right)+\gamma m^{t-2} \\
E^{*}+\alpha F\left(k^{*}, 1\right)+\beta\left(c_{0}^{*}+c_{1}^{*}\right)
\end{array}\right)
\end{gathered}
$$




$$
T_{1}^{t-1}=(1+\tau) c_{1}^{*}-\left(1-\tau_{k}\right) F_{K}\left(k^{*}, 1\right) k^{*}
$$

where $B=[\gamma+\beta(1-b)] F_{L}\left(k^{t-2}, 1\right){ }^{7}$

(2) to all generations born from period $t$ onwards

$$
\begin{gathered}
\tau=\frac{\gamma+\beta-[\gamma+\beta(1-b)] b}{\gamma b} \\
\tau_{p}=\frac{\alpha(\gamma+\beta)-\beta b^{2}(\gamma-\alpha)+\alpha \beta b}{\gamma[\gamma+\beta(1-b)]} \\
\tau_{w}=1-\frac{(1+\tau) c_{0}^{*}+k^{*}+m^{*}}{\left(1-\tau_{p}\right) F_{L}\left(k^{*}, 1\right)} \\
T_{1}=(1+\tau) c_{1}^{*}-\left(1-\tau_{p}\right) F_{K}\left(k^{*}, 1\right) k^{*}
\end{gathered}
$$

Proof: The proof for this proposition is similar to the proof for proposition 2.

\section{Conclusion}

We have presented a general equilibrium overlapping generations model with environmental externalities from both production and consumption. For such a model we proved that the competitive equilibrium steady state is not the planner's steady state, for any discount rate the social planner may use. The pollution externality from consumption does not affect the range of dynamically inefficient capital ratios, whereas the pollution externality from production does. The higher the production pollution parameter $\alpha$, the larger the inefficient range. The environmental maintaining technology $\gamma$ also plays a role in determining the best steady state capital ratio $k^{*}$. The cleaner the environment maintaining technology, the smaller the range of the dynamically inefficient allocations. By comparing the competitive steady state and the best steady state, we designed a balanced budget taxes and transfer policy that decentralizes the planner's steady state.

This paper makes many simplifying assumptions, such as the technology being exogenous, the population growth rate being zero and there being only one production sector. Further developments including endogenous technology and fertility, as well as the impact of human capital accumulation are left for future research.

\section{References}

Blanchard, O. and Fisher, S., "Lectures on Macroeconomics: Chapter 3", Massachusetts: The MIT Press, Cambridge (1989).

Chiang, Alpha C., "Fundamental Methods of Mathematical Economics: Chapter 8", McGraw-Hill, Inc. (1984), ISBN 0-07-010813-7.

\footnotetext{
${ }^{7}$ Note that this denominator is different from corresponding denominator in Proposition 4 the term $F_{L}\left(k^{t-2}, 1\right)$. This is obvious since $\tau_{w}^{t-1}$ is tax rate on income while $T_{0}^{t-1}$ is lumpsum tax on income.
} 
De la Croix, D. and Philippe, M., "A Theory of Economic Growth - Dynamics and Policy in Overlapping Generations", Cambridge University Press (2002), ISBN 978-0-521-00115-1.

Diamond, P.A., "National Debt in a Neoclassical Growth Model", The American Economic Review, Vol. 55 , No.5 (1965), pp $1126-1150$.

Gradus, R. and Smulders, S., "The Trade-off between Environmental care and long-term Growth Pollution in three Prototype Growth models", Journal of Economics, Vol. 58, No 1 (1993), pp 25 - 51.

Gutiérrez, M.J, "Dynamic inefficiency in an Overlapping Generation Economy with Pollution and Health Cost", Journal of Public Economic Theory 10 (2008), pp 563 - 594.

John, A. and Pecchenino, R., "An Overlapping Generations Model of Growth and the Environment", The Economic Journal 104 (1994), 1393 - 1410.

John, A. et al., "Short-lived agents and the long-lived environment", Journal of Public Economics 58 (1995), pp $127-141$.

Jouvet, P.A., Pestieau, P. and Ponthiere, G., "Longevity and Environmental Quality in an OLG Model", CORE Discussion Paper 2007/69.

Ono, T., "Optimal tax schemes and the environmental externality", Economics Letters 53 (1996) 283 289.

\section{Appendix}

\section{A1. Existence of the agent's optimal solution}

By substituting (10), (11), (12) and (13) into (8) and (9) the existence of solution to the system of the first order conditions (8)-(13) is equivalent to the existence of solution to the system of two following equations

$$
\begin{gathered}
u^{\prime}\left(c_{0}^{t}\right)-[\beta(1-b)+\gamma] \phi^{\prime}\left(E_{t+1}^{e}\right)=0 \\
v^{\prime}\left(c_{1}^{t}\right)-\frac{\beta+\frac{\gamma}{r_{t+1}}}{\beta(1-b)+\gamma} u^{\prime}\left(c_{0}^{t}\right)=0
\end{gathered}
$$

where

$$
\begin{aligned}
E_{t+1}^{e}= & (1-b)\left[(1-b) E_{t-1}-\alpha F\left(k_{t-1}, 1\right)-\beta\left(c_{0}^{t}+c_{1}^{t-1}\right)+\gamma m^{t-1}\right] \\
& -\alpha F\left(K_{t+1}, 1\right)-\beta\left(c_{0}^{t+1, e}+c_{1}^{t}\right)+\gamma\left(w_{t}-c_{0}^{t}-\frac{c_{1}^{t}}{r_{t+1}}\right)
\end{aligned}
$$

From (57), by implicit function theorem we can treat $c_{1}^{t}$ as a function of $c_{0}^{t}, c_{1}^{t}=\varphi\left(c_{0}^{t}\right)$ where $\varphi^{\prime}(\cdot)>0, \varphi(0)=0$ and $\varphi(+\infty)=+\infty$. We rewrite

$$
E_{t+1}^{e}=Q-[\beta(1-b)+\gamma] c_{0}^{t}-\left(\beta+\frac{\gamma}{r_{t+1}}\right) \varphi\left(c_{0}^{t}\right)
$$

where $Q=(1-b)\left[(1-b) E_{t-1}-\alpha F\left(k_{t-1}, 1\right)-\beta c_{1}^{t-1}+\gamma e^{t-1}\right]-\alpha F\left(K_{t+1}, 1\right)-\beta c_{0}^{t+1, e}+\gamma w_{t}$. Now the system of equations (56) and (57) leads to the following equation

$$
u^{\prime}\left(c_{0}^{t}\right)-[\beta(1-b)+\gamma] \phi^{\prime}\left(Q-[\beta(1-b)+\gamma] c_{0}^{t}-\left(\beta+\frac{\gamma}{r_{t+1}}\right) \varphi\left(c_{0}^{t}\right)\right)=0
$$

The existence of the agent's optimal solution is equivalent to the existence of solution to equation (58). In effect, set 


$$
\triangle=u^{\prime}\left(c_{0}^{t}\right)-[\beta(1-b)+\gamma] \phi^{\prime}\left(Q-[\beta(1-b)+\gamma] c_{0}^{t}-\left(\beta+\frac{\gamma}{r_{t+1}}\right) \varphi\left(c_{0}^{t}\right)\right)
$$

is a continuous function of $c_{0}^{t}$. We have,

$$
\lim _{c_{0}^{t} \rightarrow+\infty} \triangle=-\infty<0
$$

and

$$
\lim _{c_{0}^{t} \rightarrow 0^{+}} \triangle=+\infty>0
$$

We also find that $\triangle$ is a monotone function of $c_{0}^{t}$ since

$$
\frac{\partial \triangle}{\partial c_{0}^{t}}=u^{\prime \prime}\left(c_{0}^{t}\right)+[\beta(1-b)+\gamma]\left[\beta(1-b)+\gamma+\left(\beta+\frac{\gamma}{r_{t+1}}\right) \varphi^{\prime}\left(c_{0}^{t}\right)\right] \phi^{\prime \prime}\left(E_{t+1}^{e}\right)<0
$$

So there exists a unique solution $c_{0}^{t}>0$ to (58), meaning that there exists a unique optimal solution of the agent.

\section{A2. Checking the SOCs for the maximization problem of the agent}

For the FOCs to be sufficient conditions to characterize a (local) maximum to the optimization problem, we have to check the sufficient SOCs. The Lagrangian of the maximization problem is

$$
\begin{aligned}
Z_{t}= & u\left(c_{0}^{t}\right)+v\left(c_{1}^{t}\right)+\phi\left(E_{t+1}^{e}\right)+\lambda_{1}^{t}\left(c_{0}^{t}+k^{t}+m^{t}-w_{t}\right)+\lambda_{2}^{t}\left(c_{1}^{t}-r_{t+1} k^{t}\right) \\
& +\lambda_{3}^{t}\left(E_{t}-(1-b) E_{t-1}+\alpha F\left(k^{t-1}, 1\right)+\beta\left(c_{0}^{t}+c_{1}^{t-1}\right)-\gamma m^{t-1}\right) \\
& +\lambda_{4}^{t}\left(E_{t+1}^{e}-(1-b) E_{t}+\alpha F\left(k^{t}, 1\right)+\beta\left(c_{0}^{t+1, e}+c_{1}^{t}\right)-\gamma m^{t}\right)
\end{aligned}
$$

whose bordered Hessian will appear as

$$
\bar{H}=\left(\begin{array}{cccccccccc}
0 & 0 & 0 & 0 & 1 & 0 & 1 & 1 & 0 & 0 \\
0 & 0 & 0 & 0 & 0 & 1 & -r_{t+1} & 0 & 0 & 0 \\
0 & 0 & 0 & 0 & \beta & 0 & 0 & 0 & 1 & 0 \\
0 & 0 & 0 & 0 & 0 & \beta & 0 & -\gamma & b-1 & 1 \\
1 & 0 & \beta & 0 & u^{\prime \prime}\left(c_{0}^{t}\right) & 0 & 0 & 0 & 0 & 0 \\
0 & 1 & 0 & \beta & 0 & v^{\prime \prime}\left(c_{1}^{t}\right) & 0 & 0 & 0 & 0 \\
1 & -r_{t+1} & 0 & 0 & 0 & 0 & 0 & 0 & 0 & 0 \\
1 & 0 & 0 & -\gamma & 0 & 0 & 0 & 0 & 0 & 0 \\
0 & 0 & 1 & b-1 & 0 & 0 & 0 & 0 & 0 & 0 \\
0 & 0 & 0 & 1 & 0 & 0 & 0 & 0 & 0 & \phi^{\prime \prime}\left(E_{t+1}^{e}\right)
\end{array}\right)
$$

The sufficient SOCs for a maximum are 


$$
\begin{aligned}
& (-1)^{5}\left|\bar{H}_{5}\right|=-\left|\begin{array}{ccccccccc}
0 & 0 & 0 & 0 & 1 & 0 & 1 & 1 & 0 \\
0 & 0 & 0 & 0 & 0 & 1 & -r_{t+1} & 0 & 0 \\
0 & 0 & 0 & 0 & \beta & 0 & 0 & 0 & 1 \\
0 & 0 & 0 & 0 & 0 & \beta & 0 & -\gamma & b-1 \\
1 & 0 & \beta & 0 & u^{\prime \prime}\left(c_{0}^{t}\right) & 0 & 0 & 0 & 0 \\
0 & 1 & 0 & \beta & 0 & v^{\prime \prime}\left(c_{1}^{t}\right) & 0 & 0 & 0 \\
1 & -r_{t+1} & 0 & 0 & 0 & 0 & 0 & 0 & 0 \\
1 & 0 & 0 & -\gamma & 0 & 0 & 0 & 0 & 0 \\
0 & 0 & 1 & b-1 & 0 & 0 & 0 & 0 & 0
\end{array}\right| \\
& =-(\beta(1-b)+\gamma)^{2} r_{t+1}^{2} v^{\prime \prime}\left(c_{1}^{t}\right)-\left(\beta r_{t+1}+\gamma\right)^{2} u^{\prime \prime}\left(c_{0}^{t}\right)>0 \\
& (-1)^{6}\left|\bar{H}_{6}\right|=\left|\begin{array}{cccccccccc}
0 & 0 & 0 & 0 & 1 & 0 & 1 & 1 & 0 & 0 \\
0 & 0 & 0 & 0 & 0 & 1 & -r_{t+1} & 0 & 0 & 0 \\
0 & 0 & 0 & 0 & \beta & 0 & 0 & 0 & 1 & 0 \\
0 & 0 & 0 & 0 & 0 & \beta & 0 & -\gamma & b-1 & 1 \\
1 & 0 & \beta & 0 & u^{\prime \prime}\left(c_{0}^{t}\right) & 0 & 0 & 0 & 0 & 0 \\
0 & 1 & 0 & \beta & 0 & v^{\prime \prime}\left(c_{1}^{t}\right) & 0 & 0 & 0 & 0 \\
1 & -r_{t+1} & 0 & 0 & 0 & 0 & 0 & 0 & 0 & 0 \\
1 & 0 & 0 & -\gamma & 0 & 0 & 0 & 0 & 0 & 0 \\
0 & 0 & 1 & b-1 & 0 & 0 & 0 & 0 & 0 & 0 \\
0 & 0 & 0 & 1 & 0 & 0 & 0 & 0 & 0 & \phi^{\prime \prime}\left(E_{t+1}^{e}\right)
\end{array}\right| \\
& =r_{t+1}^{2} v^{\prime \prime}\left(c_{1}^{t}\right) u^{\prime \prime}\left(c_{0}^{t}\right)+\phi^{\prime \prime}\left(E_{t+1}^{e}\right)\left|\bar{H}_{5}\right|>0
\end{aligned}
$$

which guarantees that the solution to the agent's problem is a maximum indeed.

\section{A3. Competitive equilibrium dynamics}

The competitive equilibrium conditions impose on $\left(c_{0}^{t+1}, c_{1}^{t}, k^{t}, m^{t}, E_{t+1}\right)$ a dynamics described by a first-order difference equation, since

$$
\begin{gathered}
u^{\prime}\left(c_{0}^{t}\right)-[\beta(1-b)+\gamma] \phi^{\prime}\left(E_{t+1}\right)=0 \\
v^{\prime}\left(c_{1}^{t}\right)-\left[\beta+\frac{\gamma}{F_{K}\left(k^{t}, 1\right)}\right] \phi^{\prime}\left(E_{t+1}\right)=0 \\
c_{0}^{t}+k^{t}+m^{t}-F_{L}\left(k^{t-1}, 1\right)=0 \\
c_{1}^{t}-F_{K}\left(k^{t}, 1\right) k^{t}=0 \\
E_{t+1}-(1-b) E_{t}+\alpha F\left(k^{t}, 1\right)+\beta\left(c_{0}^{t+1}+c_{1}^{t}\right)-\gamma m^{t}=0
\end{gathered}
$$

implicitly define it to be a function of its lagged value $\left(c_{0}^{t}, c_{1}^{t-1}, k^{t-1}, m^{t-1}, E_{t}\right)$. In effect, the associated Jacobian matrix with respect to $\left(c_{0}^{t+1}, c_{1}^{t}, k^{t}, m^{t}, E_{t+1}\right)$ 


$$
J=\left(\begin{array}{ccccc}
0 & 0 & 0 & 0 & G \\
0 & v^{\prime \prime}\left(c_{1}^{t}\right) & D & 0 & H \\
0 & 0 & 1 & 1 & 0 \\
0 & 1 & -C & 0 & 0 \\
\beta & \beta & \alpha F_{K}\left(k^{t}, 1\right) & -\gamma & 1
\end{array}\right)
$$

where

$$
\begin{gathered}
C=F_{K}\left(k^{t}, 1\right)+F_{K K}\left(k^{t}, 1\right) k^{t}>0 \\
D=\frac{\gamma F_{K K}\left(k^{t}, 1\right)}{F_{K}\left(k^{t}, 1\right)^{2}} \phi^{\prime}\left(E_{t+1}\right)<0 \\
G=-[\beta(1-b)+\gamma] \phi^{\prime \prime}\left(E_{t+1}\right)>0 \\
H=-\left[\beta+\frac{\gamma}{F_{K}\left(k^{t}, 1\right)}\right] \phi^{\prime \prime}\left(E_{t+1}\right)>0
\end{gathered}
$$

is regular, since

$$
\begin{aligned}
\operatorname{det}(J) & =G\left|\begin{array}{cccc}
0 & v^{\prime \prime}\left(c_{1}^{t}\right) & D & 0 \\
0 & 0 & 1 & 1 \\
0 & 1 & -C & 0 \\
\beta & \beta & \alpha F_{K}\left(k^{t}, 1\right) & -\gamma
\end{array}\right| \\
& =-G \beta\left|\begin{array}{ccc}
v^{\prime \prime}\left(c_{1}^{t}\right) & D & 0 \\
0 & 1 & 1 \\
1 & -C & 0
\end{array}\right| \\
& =-G \beta\left[D+C v^{\prime \prime}\left(c_{1}^{t}\right)\right]>0
\end{aligned}
$$

Since, the Jacobian matrix is regular for all $\left(c_{0}^{t+1}, c_{1}^{t}, k^{t}, m^{t}, E_{t+1}\right)$ then it is evidently regular at the solution. This implies that for all competitive equilibrium $\left(c_{0}^{t+1}, c_{1}^{t}, k^{t}, m^{t}, E_{t+1}\right)_{t}$ there exists, for all $t$, a function $\psi: \mathbb{R}^{5} \rightarrow \mathbb{R}^{5}$ such that

$$
\left(\begin{array}{c}
c_{0}^{t+1} \\
c_{1}^{t} \\
k^{t} \\
m^{t} \\
E_{t+1}
\end{array}\right)=\psi\left(\begin{array}{c}
c_{0}^{t} \\
c_{1}^{t-1} \\
k^{t-1} \\
m^{t-1} \\
E_{t}
\end{array}\right)
$$




\section{A4. Solving the problem of the social planner}

The Lagrange function for this problem is

$$
\begin{gathered}
\mathcal{L}=\sum_{t=0}^{+\infty} \frac{1}{(1+R)^{t}}\left[u\left(c_{0}^{t}\right)+u\left(c_{1}^{t}\right)+\phi\left(E_{t+1}\right)\right] \\
+\sum_{t=0}^{+\infty} \frac{\mu_{t}}{(1+R)^{t}}\left[F\left(k^{t-1}, 1\right)-c_{0}^{t}-c_{1}^{t-1}-k^{t}-m^{t}\right] \\
+\sum_{t=0}^{+\infty} \frac{\eta_{t}}{(1+R)^{t}}\left[E_{t+1}-(1-b) E_{t}+\alpha F\left(k^{t}, 1\right)+\beta\left(c_{0}^{t+1}+c_{1}^{t}\right)-\gamma m^{t}\right]
\end{gathered}
$$

The FOCs of the maximization problem are

$$
\begin{gathered}
\frac{\partial \mathcal{L}}{\partial c_{0}^{t}}=\frac{u^{\prime}\left(c_{0}^{t}\right)}{(1+R)^{t}}-\frac{\mu_{t}}{(1+R)^{t}}+\frac{\beta \eta_{t-1}}{(1+R)^{t-1}}=0 \\
\frac{\partial \mathcal{L}}{\partial c_{1}^{t}}=\frac{v^{\prime}\left(c_{1}^{t}\right)}{(1+R)^{t}}-\frac{\mu_{t+1}}{(1+R)^{t+1}}+\frac{\beta \eta_{t}}{(1+R)^{t}}=0 \\
\frac{\partial \mathcal{L}}{\partial E_{t+1}}=\frac{\phi^{\prime}\left(E_{t+1}\right)}{(1+R)^{t}}+\frac{\eta_{t}}{(1+R)^{t}}-\frac{\eta_{t+1}(1-b)}{(1+R)^{t+1}}=0 \\
\frac{\partial \mathcal{L}}{\partial k^{t}}=-\frac{\mu_{t}}{(1+R)^{t}}+\frac{\mu_{t+1} F_{K}\left(k^{t}, 1\right)}{(1+R)^{t+1}}+\frac{\eta_{t} \alpha F_{K}\left(k^{t}, 1\right)}{(1+R)^{t}}=0 \\
\frac{\partial \mathcal{L}}{\partial m^{t}}=-\frac{\mu_{t}}{(1+R)^{t}}-\frac{\eta_{t} \gamma}{(1+R)^{t}}=0
\end{gathered}
$$

that is to say

$$
\begin{gathered}
u^{\prime}\left(c_{0}^{t}\right)-\mu_{t}+\beta \eta_{t-1}(1+R)=0 \\
v^{\prime}\left(c_{1}^{t}\right)-\frac{\mu_{t+1}}{1+R}+\beta \eta_{t}=0 \\
\phi^{\prime}\left(E_{t+1}\right)+\eta_{t}-\frac{\eta_{t+1}(1-b)}{1+R}=0 \\
-\mu_{t}+\frac{\mu_{t+1} F_{K}\left(k^{t}, 1\right)}{1+R}+\eta_{t} \alpha F_{K}\left(k^{t}, 1\right)=0 \\
-\mu_{t}-\eta_{t} \gamma=0
\end{gathered}
$$

At the steady state,

$$
u^{\prime}\left(\bar{c}_{0}\right)=\mu-\beta \eta(1+R)
$$




$$
\begin{aligned}
v^{\prime}\left(\bar{c}_{1}\right) & =\frac{\mu}{1+R}-\beta \eta \\
\phi^{\prime}(\bar{E}) & =-\eta+\frac{(1-b) \eta}{1+R} \\
F_{K}(\bar{k}, 1) & =\frac{\mu(1+R)}{\mu+\alpha \eta(1+R)} \\
\mu & =-\eta \gamma
\end{aligned}
$$

Therefore,

$$
\begin{gathered}
u^{\prime}\left(\bar{c}_{0}\right)=(1+R) \frac{\gamma+\beta(1+R)}{b+R} \phi^{\prime}(\bar{E}) \\
v^{\prime}\left(\bar{c}_{1}\right)=\frac{\gamma+\beta(1+R)}{b+R} \phi^{\prime}(\bar{E}) \\
F_{K}(\bar{k}, 1)=\frac{\gamma(1+R)}{\gamma-(1+R) \alpha}
\end{gathered}
$$




\section{Recent titles \\ CORE Discussion Papers}

2010/76. Ana MAULEON, Vincent VANNETELBOSCH and Cecilia VERGARI. Unions' relative concerns and strikes in wage bargaining.

2010/77. Ana MAULEON, Vincent VANNETELBOSCH and Cecilia VERGARI. Bargaining and delay in patent licensing.

2010/78. Jean J. GABSZEWICZ and Ornella TAROLA. Product innovation and market acquisition of firms.

2010/79. Michel LE BRETON, Juan D. MORENO-TERNERO, Alexei SAVVATEEV and Shlomo WEBER. Stability and fairness in models with a multiple membership.

2010/80. Juan D. MORENO-TERNERO. Voting over piece-wise linear tax methods.

2010/81. Jean HINDRIKS, Marijn VERSCHELDE, Glenn RAYP and Koen SCHOORS. School tracking, social segregation and educational opportunity: evidence from Belgium.

2010/82. Jean HINDRIKS, Marijn VERSCHELDE, Glenn RAYP and Koen SCHOORS. School autonomy and educational performance: within-country evidence.

2010/83. Dunia LOPEZ-PINTADO. Influence networks.

2010/84. Per AGRELL and Axel GAUTIER. A theory of soft capture.

2010/85. Per AGRELL and Roman KASPERZEC. Dynamic joint investments in supply chains under information asymmetry.

2010/86. Thierry BRECHET and Pierre M. PICARD. The economics of airport noise: how to manage markets for noise licenses.

2010/87. Eve RAMAEKERS. Fair allocation of indivisible goods among two agents.

2011/1. Yu. NESTEROV. Random gradient-free minimization of convex functions.

2011/2. Olivier DEVOLDER, François GLINEUR and Yu. NESTEROV. First-order methods of smooth convex optimization with inexact oracle.

2011/3. Luc BAUWENS, Gary KOOP, Dimitris KOROBILIS and Jeroen V.K. ROMBOUTS. A comparison of forecasting procedures for macroeconomic series: the contribution of structural break models.

2011/4. Taoufik BOUEZMARNI and Sébastien VAN BELLEGEM. Nonparametric Beta kernel estimator for long memory time series.

2011/5. Filippo L. CALCIANO. The complementarity foundations of industrial organization.

2011/6. Vincent BODART, Bertrand CANDELON and Jean-François CARPANTIER. Real exchanges rates in commodity producing countries: a reappraisal.

2011/7. Georg KIRCHSTEIGER, Marco MANTOVANI, Ana MAULEON and Vincent VANNETELBOSCH. Myopic or farsighted? An experiment on network formation.

2011/8. Florian MAYNERIS and Sandra PONCET. Export performance of Chinese domestic firms: the role of foreign export spillovers.

2011/9. Hiroshi UNO. Nested potentials and robust equilibria.

2011/10. Evgeny ZHELOBODKO, Sergey KOKOVIN, Mathieu PARENTI and Jacques-François THISSE. Monopolistic competition in general equilibrium: beyond the CES.

2011/11. Luc BAUWENS, Christian HAFNER and Diane PIERRET. Multivariate volatility modeling of electricity futures.

2011/12. Jacques-François THISSE. Geographical economics: a historical perspective.

2011/13. Luc BAUWENS, Arnaud DUFAYS and Jeroen V.K. ROMBOUTS. Marginal likelihood for Markov-switching and change-point GARCH models.

2011/14. Gilles GRANDJEAN. Risk-sharing networks and farsighted stability.

2011/15. Pedro CANTOS-SANCHEZ, Rafael MONER-COLONQUES, José J. SEMPERE-MONERRIS and Oscar ALVAREZ-SANJAIME. Vertical integration and exclusivities in maritime freight transport.

2011/16. Géraldine STRACK, Bernard FORTZ, Fouad RIANE and Mathieu VAN VYVE. Comparison of heuristic procedures for an integrated model for production and distribution planning in an environment of shared resources. 


\section{Recent titles}

\section{CORE Discussion Papers - continued}

2011/17. Juan A. MAÑEZ, Rafael MONER-COLONQUES, José J. SEMPERE-MONERRIS and Amparo URBANO Price differentials among brands in retail distribution: product quality and service quality.

2011/18. Pierre M. PICARD and Bruno VAN POTTELSBERGHE DE LA POTTERIE. Patent office governance and patent system quality.

2011/19. Emmanuelle AURIOL and Pierre M. PICARD. A theory of BOT concession contracts.

2011/20. Fred SCHROYEN. Attitudes towards income risk in the presence of quantity constraints.

2011/21. Dimitris KOROBILIS. Hierarchical shrinkage priors for dynamic regressions with many predictors.

2011/22. Dimitris KOROBILIS. VAR forecasting using Bayesian variable selection.

2011/23. Marc FLEURBAEY and Stéphane ZUBER. Inequality aversion and separability in social risk evaluation.

2011/24. Helmuth CREMER and Pierre PESTIEAU. Social long term care insurance and redistribution.

2011/25. Natali HRITONENKO and Yuri YATSENKO. Sustainable growth and modernization under environmental hazard and adaptation.

2011/26. Marc FLEURBAEY and Erik SCHOKKAERT. Equity in health and health care.

2011/27. David DE LA CROIX and Axel GOSSERIES. The natalist bias of pollution control.

2011/28. Olivier DURAND-LASSERVE, Axel PIERRU and Yves SMEERS. Effects of the uncertainty about global economic recovery on energy transition and $\mathrm{CO}_{2}$ price.

2011/29. Ana MAULEON, Elena MOLIS, Vincent J. VANNETELBOSCH and Wouter VERGOTE. Absolutely stable roommate problems.

2011/30. Nicolas GILLIS and François GLINEUR. Accelerated multiplicative updates and hierarchical als algorithms for nonnegative matrix factorization.

2011/31. Nguyen Thang DAO and Julio DAVILA. Implementing steady state efficiency in overlapping generations economies with environmental externalities.

\section{Books}

P. VAN HENTENRYCKE and L. WOLSEY (eds.) (2007), Integration of AI and OR techniques in constraint programming for combinatorial optimization problems. Berlin, Springer.

P-P. COMBES, Th. MAYER and J-F. THISSE (eds.) (2008), Economic geography: the integration of regions and nations. Princeton, Princeton University Press.

J. HINDRIKS (ed.) (2008), Au-delà de Copernic: de la confusion au consensus ? Brussels, Academic and Scientific Publishers.

J-M. HURIOT and J-F. THISSE (eds) (2009), Economics of cities. Cambridge, Cambridge University Press.

P. BELLEFLAMME and M. PEITZ (eds) (2010), Industrial organization: markets and strategies. Cambridge University Press.

M. JUNGER, Th. LIEBLING, D. NADDEF, G. NEMHAUSER, W. PULLEYBLANK, G. REINELT, G. RINALDI and L. WOLSEY (eds) (2010), 50 years of integer programming, 1958-2008: from the early years to the state-of-the-art. Berlin Springer.

G. DURANTON, Ph. MARTIN, Th. MAYER and F. MAYNERIS (eds) (2010), The economics of clusters Lessons from the French experience. Oxford University Press.

J. HINDRIKS and I. VAN DE CLOOT (eds) (2011), Notre pension en heritage. Itinera Institute.

\section{CORE Lecture Series}

D. BIENSTOCK (2001), Potential function methods for approximately solving linear programming problems: theory and practice.

R. AMIR (2002), Supermodularity and complementarity in economics.

R. WEISMANTEL (2006), Lectures on mixed nonlinear programming. 